\title{
Should the Euro Area be Run as a Closed Economy?*
}

\author{
Carlo Favero and Francesco Giavazzi ${ }^{\dagger}$
}

January 2008

The European Economic and Monetary Union (EMU) has created a new economic area, larger and closer with respect to the rest of the world. Area-specific shocks are thus more important in EMU than country-specific shocks used to be in the previous states, e.g. in Germany. It is thus not surprising that the models built by the staff of the European Central Bank (ECB) to study optimal monetary policy in the Euro area (for instance Smets and Wouters, 2004a, 2004b) typically assume that this works essentially as a closed economy, hit by domestic shocks - the same assumption made in standard models of U.S. monetary policy (see e.g. Christiano et al., 1999 ), where all shocks are domestic with the only possible exception of energy price shocks. Twocountry models exist at the ECB (e.g. de Walque, Smets, Wouters, 2005) but they overlook asset price fluctuations and their international comovements.

This paper studies monetary policy in the Euro area looking at the variable most directly related to current and expected monetary policy, the yield on long term government bonds. We explore how the behavior of European long-term rates has been affected by EMU and whether the response of long-term rates to monetary policy has got any closer to that consistent with a closed economy.

We find that the level of long-term rates in Europe is almost entirely explained by U.S. shocks and by the systematic response of U.S. and European variables (inflation, short term rates and the output gap) to these shocks. Our results suggest in particular that U.S. variables are more important than local variables in the policy rule followed by European monetary authorities: this was true for the Bundesbank before EMU and has remained true for the ECB, at least so far. Using closed economy models to analyze monetary policy in the Euro is thus inconsistent with the empirical evidence on the determinants of Euro area long-term rates. It is also inconsistent with the way the Governing Council of the ECB appears to make actual policy decisions.

\footnotetext{
${ }^{*}$ Fortcoming in American Economic Review - Papers and Proceedings, May 2008.

${ }^{\dagger}$ IGIER-Univeristà Bocconi and CEPR; IGIER-Università Bocconi, MIT, CEPR and NBER
} 
We also find that Euro area long rates respond more to financial shocks, in particular shocks to term premia, than they do to monetary policy "shocks"-i.e. instances when the ECB deviates from its rule. This finding point to the importance of incorporating into the analysis of Euro area monetary policy of the effects of fluctuations in international asset prices.

\section{Long rates: has EMU made a difference?}

Figure 1 shows the evolution of Euro area and U.S. long term interest rates over the past three decades. We measure long rates in the Euro area with the yield on 10-year German benchmark government bonds: we thus abstract from credit and liquidity spreads that vary both among Euro sovereign bonds issued by different governments and between corporate and sovereign bond. Along with European long rates Figure 1 shows the evolution of U.S. long rates: the 10-year benchmark U.S. Treasury. We note two facts: (i) the correlation between European and U.S. yields has always been high, (ii) the levels of the two yields, which were different in the 1980s, have converged to the same unconditional mean since the early 1990s.

To understand why Euro area and U.S. long rates are so highly correlated and why they have converged, we decompose them into their systematic component-i.e. the response of long rates to other macro and policy variables - -and the shocks that affect them. We do so by considering the following Vector AutoRegression:

$$
\mathbf{y}_{t}=\mathbf{A}_{t}(L) \mathbf{y}_{t-1}+\mathbf{u}_{t}
$$

where $\mathbf{y}_{t}=\left[\begin{array}{llllllll}\mathbf{y}_{t}^{U S} & \boldsymbol{\pi}_{t}^{U S} & i_{t, t+1}^{U S} & i_{t, t+120}^{U S} & \mathbf{y}_{t}^{E U-G E R} & \boldsymbol{\pi}_{t}^{E U-G E R} & i_{t, t+1}^{G E R} & i_{t, t+120}^{G E R}\end{array}\right]^{\prime}$

$$
\mathbf{A}=\left[\begin{array}{cc}
\mathbf{A}_{11} & \mathbf{0} \\
\mathbf{A}_{21} & \mathbf{A}_{22}
\end{array}\right]
$$

$\mathbf{y}_{t}^{U S}$ and $\mathbf{y}_{t}^{E U-G E R}$ are measures of the output gap computed by applying the HodrickPrescott filter to the logarithm of industrial production (the filter is one-sided and is computed recursively in real time, that is the output gap at time $t$ uses only information available at time $t) \cdot \mathbf{y}_{t}^{E U-G E R}$ is obtained using German industrial production up to 1998:12 and Euro area industrial production from 1999:1 onward. $\boldsymbol{\pi}_{t}^{U S}$ and $\boldsymbol{\pi}_{t}^{E U-G E R}$ are annual inflation rates (based on consumers prices). $\boldsymbol{\pi}_{t}^{E U-G E R}$ is obtained by considering German data up to 1998:12 and the Euro area HCPI index from 1999:1 onward. $i_{t, t+1}^{U S}, i_{t, t+1}^{G E R}$ are the policy rates: the Federal Funds rate for the U.S., the German policy rate up to 1999:1, and the Euro area overnight rate thereafter. 
The long-term rates, $i_{t, t+120}^{U S}, i_{t, t+120}^{G E R}$, are the yields to maturity on 10-year benchmark U.S. and German government bonds.

Imposing $\mathbf{A}_{12}=0$ we make the assumption that U.S. variables do not respond to Euro area variables - an assumption consistent with the evidence suggesting that the U.S. behaves by and large as a closed economy. Finally, the lag length of the VAR is decided on the basis of standard selection criteria.

To study whether EMU has made a difference to long rates in the Euro area we run the following counterfactual experiment. The assumption $\mathbf{A}_{12}=0$ is sufficient to identify the shocks originating in the U.S. and those originating in the Euro area. We can thus ask what would Euro area long rates have looked like had the region been hit only by U.S. shocks. To build these artificial interest rates we set to zero the Euro area shocks and simulate the model using only the four U.S. shocks and the systematic response of all variables to them. To allow for the possibility that parameter values differ among sub-periods (the 1980s were characterized by a pegged exchange rate regime; in the 90's European exchange rates were essentially flexible, after the devaluations of 1992 and were later characterized by the transition to EMU which started in 1999:1) we run the counterfactual experiment estimating the VAR over three separate sub-samples: the 1980s, the 1990s, and the period since 1999:1.

Figure 2 shows the result. The artificial rates are virtually identical to the historical rates: In other words, the level of German long-term rates is explained almost perfectly by U.S. shocks and by the systematic response of U.S. and European variables to them. This was true before EMU and continues to be true today: there is no visual evidence of a break between the pre-EMU and the post-EMU sample. The lesson we draw from this exercise is that the models used to analyze monetary policy in the Euro area should not overlook the transmission to the area of shocks which originate in the U.S., because such shocks are determine the behavior of European variables, including the policy rule followed by the monetary authorities.

\section{Euro long rates and financial shocks}

The exercise in the previous section studies the effect of innovations in U.S. variables on euro area long-rates, without identifying the underlying structural shocks. To better understand the determinants of long rates we now consider how they respond to structural shocks. To do this we need additional identifying assumptions beyond $\mathbf{A}_{21}=0$. We identify four financial shocks: two monetary policy and two nonmonetary policy shocks, respectively in the U.S. and in the Euro area. Monetary 
policy shocks are deviations from the systematic response of the two central banks to macroeconomic variables. Non monetary financial shocks - as we shall learn from impulse responses - are shocks to term premia: thus from now on we shall refer to them as "term premia shocks". We do not identify the shocks to the two macro variables, inflation and the output gap: we just consider them as macro shocks.

We make the following assumption on the contemporaneous relations among the variables in the VAR: all macro variables react with at least a one-month lag to financial variables. Financial variables react simultaneously to macroeconomic developments. Monetary policy does not react to financial shocks in the month they happen. The recursive structure between to U.S. and the Euro $\left(\mathbf{A}_{21}=0\right)$ is assumed to hold also for the simultaneous relation among shocks.

Imposing these identification assumptions on the relation, $C \boldsymbol{\epsilon}=B \mathbf{u}$, between the the eight VAR residuals $u$ and the structural shocks

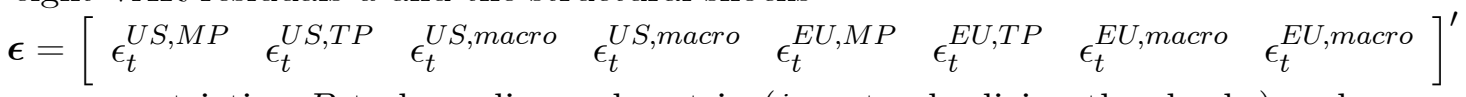

means restricting $B$ to be a diagonal matrix (i.e. standardizing the shocks) and imposing upon $C$ the appropriate restrictions ${ }^{1}$

Table 1 summarizes the effects of the structural shocks on Euro area long rates The entries in the table are the forecasting errors when we use our VAR to predict long rates in the future. Our identification assumptions allow us to decompose the variance of these forecasting errors in six orthogonal components: monetary policy, term premia and macro shocks (a combination of shocks to inflation and output gaps) in the U.S. and in the Euro area. We compute the variance of the forecasting error at two different horizons: one-month ahead and 120-months (ten years) ahead. The exercise is repeated for three subsamples.

\footnotetext{
${ }^{1}$ These assumptions are often used to identify U.S. monetary policy shocks (see, for example, Christiano et al. 1999) and shocks to U.S. long-term rates (see Evans and Marshall, 1998 and Edelberg and Marshall, 1996). The restrictions they imply satisfy the rank and order conditions for identification discussed in Amisano and Giannini (1997).
} 


\begin{tabular}{|l|l|l|l|l|l|l|l|}
\hline \multicolumn{2}{|c|}{ Table 1: Variance decomposition of European 10-year rates } \\
\hline \hline & & \multicolumn{3}{|c|}{ U.S. shocks } & \multicolumn{3}{|c|}{ Euro area shocks } \\
\hline \hline sample & & macro & MP & TP & macro & MP & TP \\
\hline \hline $\mathbf{7 9 - 8 9}$ & 1 -step & 0.09 & 0.06 & 0.21 & 0.02 & 0.01 & 0.62 \\
\hline & 120 -step & 0.35 & 0.11 & 0.24 & 0.11 & 0.05 & 0.14 \\
\hline $\mathbf{9 0 - 9 8}$ & 1 -step & 0.03 & 0.01 & 0.11 & 0.04 & 0.01 & 0.80 \\
\hline & 120 -step & 0.27 & 0.01 & 0.25 & 0.33 & 0.01 & 0.12 \\
\hline $\mathbf{9 9 - 0 7}$ & 1 -step & 0.01 & 0.01 & 0.38 & 0.05 & 0.01 & 0.57 \\
\hline & 120 -step & 0.12 & 0.06 & 0.18 & 0.30 & 0.04 & 0.30 \\
\hline
\end{tabular}

Two findings emerge from Table 1: (i) the 1-month ahead forecasting error is always almost totally explained by a combination of U.S. and Euro area term premia shocks; the forecasting variance of long rates attributable to monetary policy shocks is small, both at the short and long (10 year) horizon. This is true in EMU as it was in the two previous decades; (ii) since the start of EMU the share of the forecasting variance (at the 10-year horizon) attributable to Euro area idiosyncratic macro and term premia shocks has increased. In the 1999-2007 sample 60\% $(0.30+$ 0.30 ) of the variance of the forecasting error at a 10-year horizon is attributable to local non-monetary policy shocks; this share was $45 \%$ in the previous decade $(0.33+$ 0.12) . Thus, when Euro area long rates deviate from their systematic component $\left(\mathbf{A}_{t}(L) \mathbf{y}_{t-1}\right.$ in (1)) this is mainly because of shocks to the local and U.S.term premia and to local macro variables.

To better understand the effects of financial shocks on long rates we next analyze impulse responses.

\subsection{Term premia shocks}

To construct an estimate of the term premium we decompose the nominal yield at time $t$ on a $T-t$-year bond coming to maturity at time $T, i_{t, T}$, in the weighted sequence of expected future policy rates - which we denoted with $i_{t, T}^{*}$-and a term premium.

$$
\begin{aligned}
i_{t, T} & =i_{t, T}^{*}+T P_{t, T} \\
& =\frac{1-\gamma}{1-\gamma^{T-t}} \sum_{j=1}^{T} \gamma^{j-1} E_{t} i_{t+j-1, t+j}+T P_{t, T}
\end{aligned}
$$

Equation (2) applies the linearized expectations model of Shiller (1979). It is 
derived from a no-arbitrage condition: expected one-period returns from holding a long-term bond must be equal to the one-period risk-free interest rate, plus a oneperiod term premium. For long term bonds bearing a coupon $C$, the one-period holding-return is a non-linear function of the yield to maturity $i_{t, T}$. Following Shiller we linearize (2) in the neighborhood of $i_{t, T}=i_{t+1, T}=\bar{R}=C$

$$
E\left[h_{t, T} \mid I_{t}\right]=E\left[\frac{i_{t, T}-\gamma_{T} i_{t+1, T}}{1-\gamma_{T}} \mid I_{t}\right]=i_{t, t+1}+\phi_{t, T}
$$

where $h_{t, T}$ is the one-period holding return of a bond with maturity date $T, I_{t}$ is the information set available to agents at time $t, i_{t, t+1}$ is the short-term (one-period) risk free interest rate, $\gamma_{T}$ is a constant arising from the linearization of (2) and which depends on the maturity of the bond. (For long-term bond such a constant can be approximated by $1 /(1+\bar{R})$, since $\left.\lim _{T \longrightarrow \infty} \gamma_{T}=\gamma=1 /(1+\bar{R})\right) . \phi_{t, T}$ is the term premium - defined over a one-period horizon - required for holding for one period a bond with residual maturity $T-t$. Solving equation (3) forward we obtain (2), where $T P_{t, T}$ is the term premium over the entire residual life of the bond.

To compute (2) we need forecasts of future policy rates. Denoting with $\mathbf{Z}_{t}=$ $\mathbf{A}_{t} \mathbf{Z}_{t-1}+\mathbf{u}_{t}$ the stacked representation of our estimated VARs, we construct $i_{t, T}^{*, U S}$, and $i_{t, T}^{*, E U-G E R}$ as follows

$$
\begin{aligned}
i_{t, T}^{*, U S} & =\frac{1-\gamma_{U S}}{1-\gamma_{U S}^{T-t}} \sum_{j=1}^{t+120} \gamma_{U S}^{j-1} e_{3}^{\prime} \mathbf{A}_{t}^{j-1} \mathbf{Z}_{t} \\
i_{t, T}^{*, E U-G E R} & =\frac{1-\gamma_{G E R}{ }^{t+120}}{1-\gamma_{G E R}^{T-t}} \sum_{j=1}^{j-1} \gamma_{G E R} e_{7}^{\prime} \mathbf{A}_{t}^{j-1} \mathbf{Z}_{t}
\end{aligned}
$$

and generate the term premia as residuals. The validity of our estimated term premia obviously depends on how closely the expectations for future short term rates, constructed with our VAR, track the true agents expectations.

Figure 3 shows that the non monetary financial shocks - to U.S. and Euro area long-term rates - that we have identifies are indeed shocks to their respective term premia. The impulse responses of 10-year yields and term premia to such shocks are virtually identical, for all the three sub-samples.

\subsection{Monetary policy shocks}

We have learned from the variance decomposition that monetary policy shocks are not the main determinant of Euro area long-term rates. Still it is interesting to assess 
the response of long rates to such shocks (i.e. to deviations of the central bank from its systematic "rule") because this allows us to assess if there are any differences between the response of U.S. long-term rates to U.S. monetary policy shocks, and the response of Euro area long-term rates to policy shocks induced by the ECB (and by the Bundesbank prior to 1999). The results are in Figures 4 and 5. Figure 4 reports the responses of 10-year rates and term premia-both in the U.S. and in the Euro area-to a U.S. monetary policy shock. Figure 5 repeats the exercise for a Euro area monetary policy shock.

As observed by Roush (2007), the Expectations Theory works in the U.S. conditional upon monetary policy shocks: a U.S. monetary policy shock (Figure 4) does not generate a significant response of the U.S. term premium. This is not the case for monetary policy shocks induced by the ECB (and by the Bundesbank prior to 1999) shown in Figure 5. In the 1990-98 sample, when the Bundesbank was in charge, following a contractionary monetary innovation the bond market rallied (the impulse responses suggest that this was the result of a fall in term premia that more than compensated the increase in expected policy rates); this pattern reverses when monetary policy starts been run by the ECB: following a contractionary monetary innovation the bond market falls, as term premia and expected monetary policy both move in the same direction (up).

The lesson we draw from this analysis is that he ECB should minimize surprises. The central bank affects long rates only through the systematic component of its monetary policy - which, as we have seen, mostly responds to U.S. variables; when it produces a surprise the effect is small, but term premia and long rates move in the same direction (up in the case of a surprise tightening), suggesting that the ECB enjoys less credibility than the FED or the Bundesbank.

\section{Conclusions}

The finding that Euro area long rates respond more to financial shocks, in particular shocks to term premia, than they do to monetary policy "shocks"-i.e. instances when the ECB deviates from its rule points to the importance of incorporating into the analysis of Euro area monetary policy of the effects of fluctuations in international asset prices. They also suggest that the ability of the ECB to affect macro fluctuations could be limited. Asset price fluctuations and their international comovements are currently absent from the main DSGE models employed at the ECB: extending them should be a priority of the bank's staff. 


\section{References}

[1] Amisano, G. and C. Giannini (1997), Topics in Structural VAR Econometrics, Springer-Verlag.

[2] Christiano, L., Eichenbaum M. and and C. Evans (1999), "Monetary policy shocks: what have we learnt and to what end?", in J. Taylor and M. Woodford (eds.), Handbook of Macroeconomics, Vol. IA, Ch. 2, Amsterdam: North Holland.

[3] de Walque G., F.Smets and R.Wouters (2005), "An Estimated Two-Country DSGE Model for the Euro Area and the U.S. Economy", available at http://www.eea-esem.com/files/papers/EEA-ESEM/2006/1119/EA_US.pdf

[4] Edelberg, W. and D. A. Marshall (1996), "Monetary Policy Shocks and long-term interest rates", Federal Reserve of Chicago, Economic Perspectives, Spring.

[5] Evans C. L. and D. A. Marshall (1998), "Monetary Policy and the Term Structure of Nominal Interest Rates: Evidence and Theory", Carnegie-Rochester Conference Series on Public Policy, vol. 49.

[6] Roush, J. (2007), "The Expectations Theory Works for Monetary Policy Shocks," Journal of Monetary Economics (forthcoming).

[7] Shiller,R. (1979), "The Volatility of Long Term Interest Rates and Expectations Models of the Term Stucture", Journal of Political Economy 87, 1190-1219.

[8] Smets F. and R.Wouters (2004a), "Forecasting with a Bayesian DSGE model. An application to the Euro Area", ECB working paper no 389.

[9] Smets F. and R.Wouters (2004b), "Comparing Shocks and Frictions in the U.S. and the Euro area Business Cycle. A Bayesian DSGE approach", ECB working paper no. 391. 


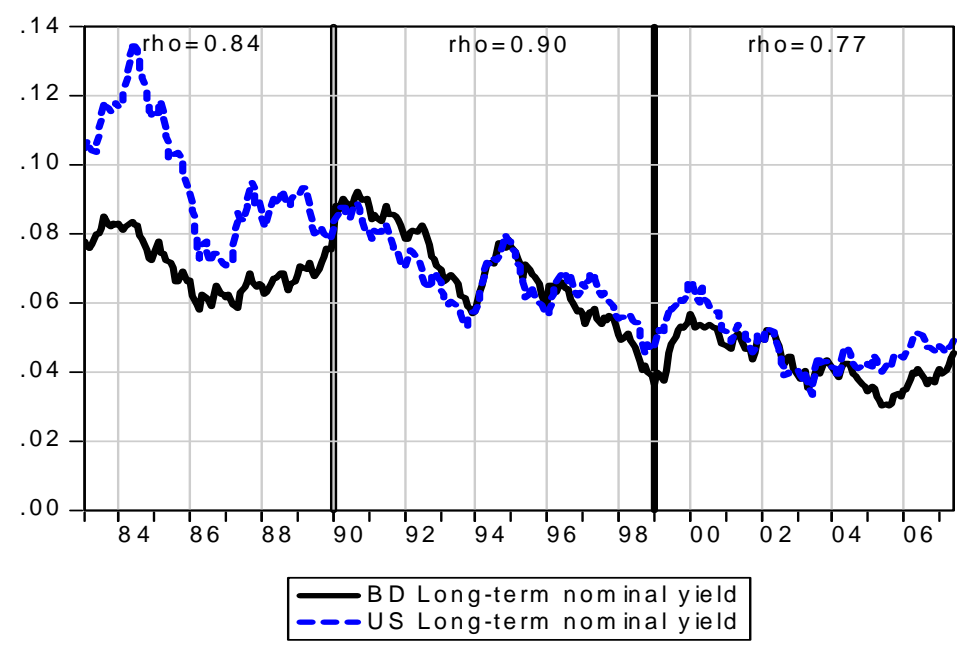

Figure 1: Yields to maturity on U.S. and German $10 \mathrm{Y}$ benchmark bonds $(r h o)$ is the correlation coefficient between the two series.

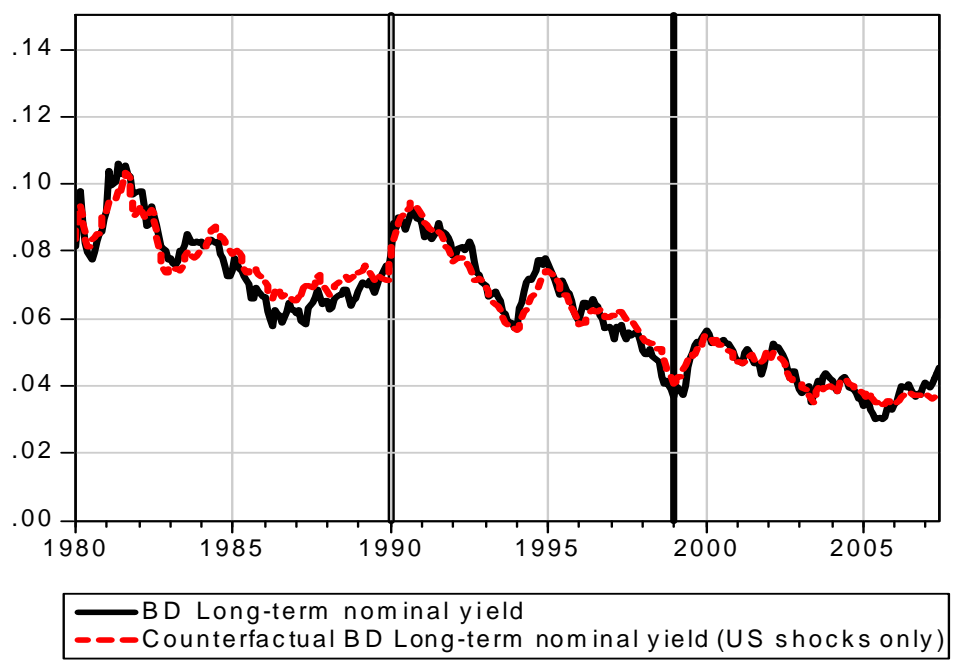

Figure 2. Counterfactual: Euro area long rates constructed using U.S. shocks only 

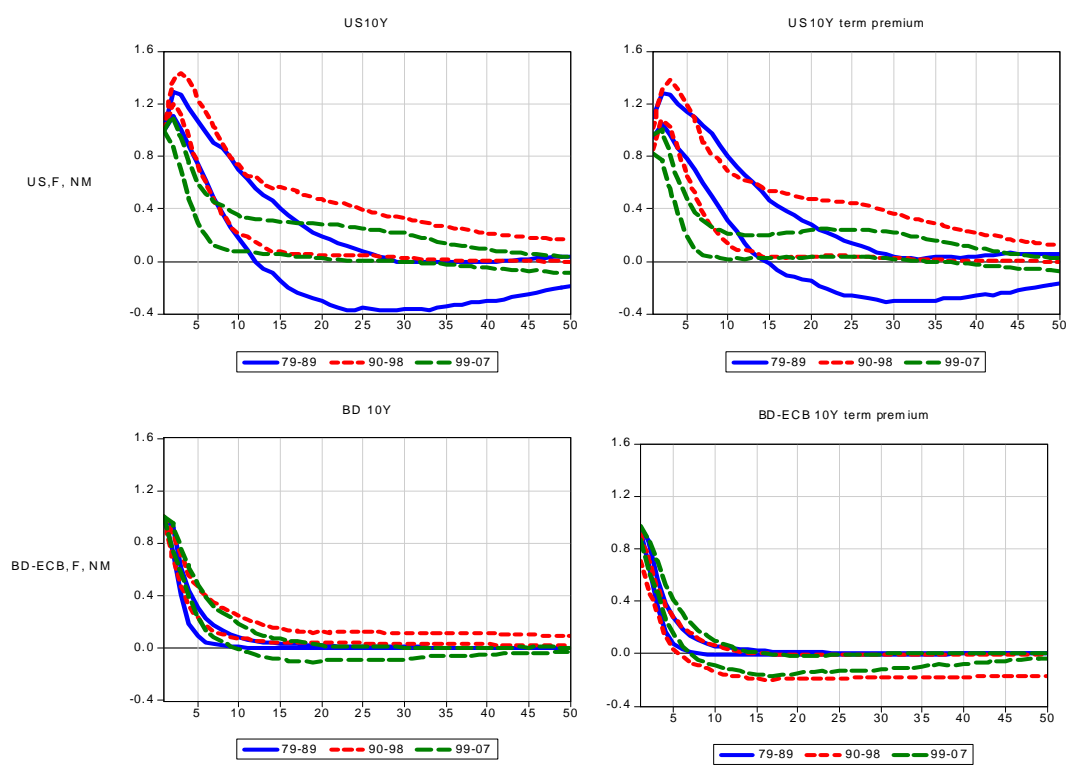

Figure 3: Financial Non-Monetary Policy Shocks are shocks to the Term Premium
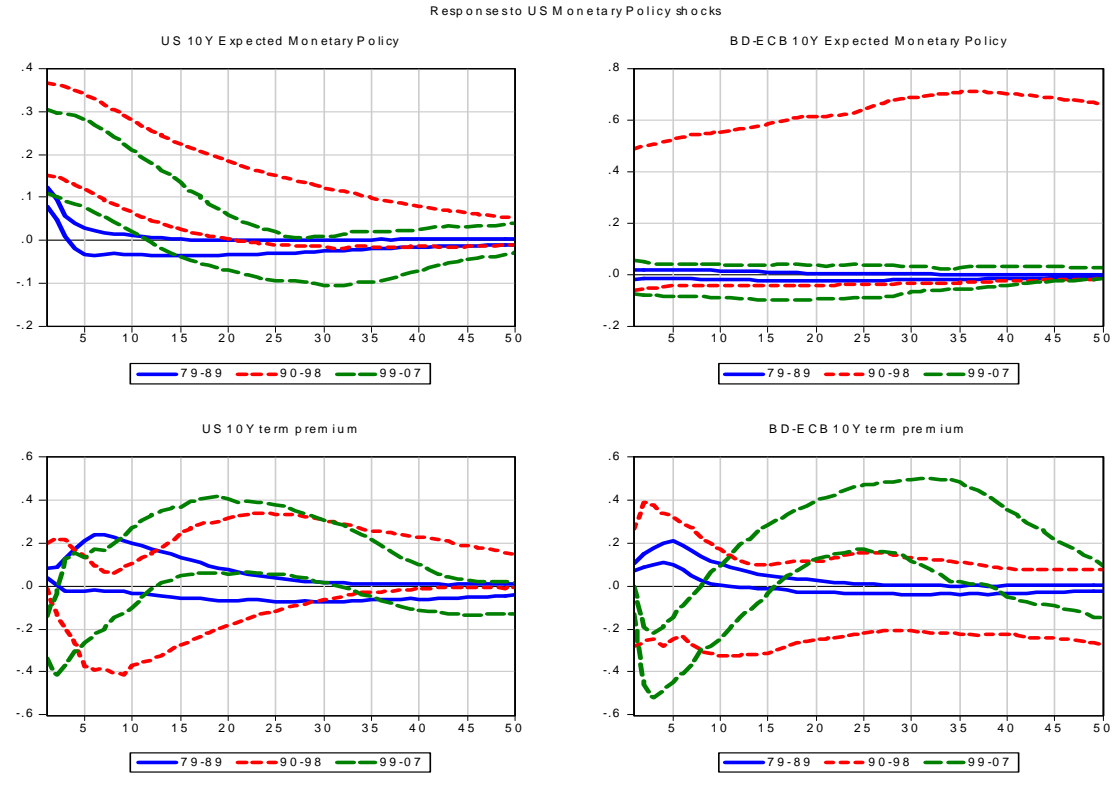

Figure 4: Responses to a FED monetary policy shock 

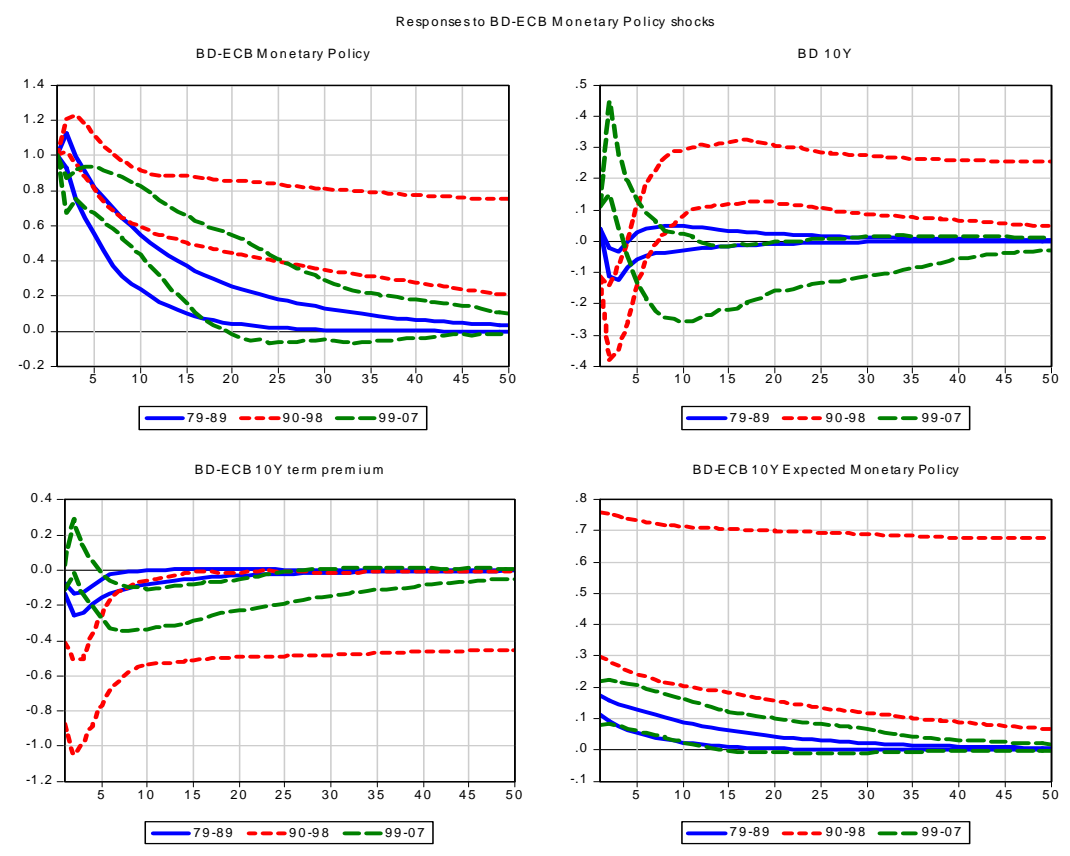

Figure 5: Responses to a Bundesbank-ECB monetary policy shock 